\title{
LA ESCRITURA DEL DETRITUS EN SAMUEL BECKETT: AL FINAL NO SE HABRÁ DICHO NADA, AÚN ${ }^{1}$
}

\author{
Sergio Rojas $C$. \\ Universidad de Chile \\ sergiorojas_s21@yahoo.com.ar \\ "Me confirmaba con sus libritos, \\ cada vez más pequeños, \\ con sus textos cada vez más cortos, \\ que la existencia para él realmente era la lengua" \\ R. Konstantinovic (2001)
}

\section{RESUMEN / ABSTRACT}

La dificultad que presenta la obra de Beckett al ejercicio de interpretación no se debe especialmente a cuestiones de contenido filosófico (habitualmente referido al horizonte del existencialismo de postguerra), sino a su reflexión formal del lenguaje. Se trata de la progresiva devastación del poder de significación de las palabras. Abordamos en el presente artículo ese proceso, en relación con el agotamiento del yo como subjectum en la trilogía narrativa Molloy, Malone muere y El Innombrable.

Palabras Clave: Beckett, Molloy, Malone, El innombrable, lenguaje, yo, detritus.

$1 \quad$ El presente artículo es producto del Proyecto de Investigación Fondecyt Regular $n^{\circ} 1151049$ (2015-2016): "La ficción del sujeto: el agotamiento del cogito en la escritura de Samuel Beckett", del cual el autor es Investigador Responsable. 
The complexities presented by the exercise of interpretation on Beckett's work are not due only to questions of philosophical content (i.e. The horizon of Postwar Existentialism), but to his formal approach to language reflection. Namely, words go through a progressive devastation at the core of their significance and connotative reach. This article further explores that process, and the exhaustion of the self as subject in the narrative trilogy Molloy, Malone Dies and The Unnamable.

KEYWORDS: Beckett, Molloy, Malone, The Unnameable, language, self, detritus.

\section{EL EQUÍVOCO COEFICIENTE "FILOSÓFICO” DE LA ESCRITURA DE BECKETT}

Resulta en cierto modo paradójica la dificultad de comprensión que suele señalarse respecto a la obra de Samuel Beckett, si se la contrasta con el minimalismo de sus personajes, historias y escenas. La dificultad es el efecto de un sostenido afán teorético especulativo que se ejercita en la extracción de significados ocultos. Ocurre, en efecto, como si en cada caso el lector o espectador se encontrara ante una especie de sentido escondido, cifrado. "Beckett, en cambio -señala Cronin acerca de Fin de partie-, quería que las palabras se dijeran con toda sencillez, con una voz neutra y con un grito inesperado de vez en cuando. 'No hay dramatismo de ninguna clase en Fin de partie -dijo a [Roger] Blin-. Hay una montaña de palabras, pero no hay dramatismo"' (Cronin 476). Podría decirse que Beckett antes que sancionar simplemente como inadecuado dicho afán hermenéutico, más bien lo confronta desde el manejo formal que hace del lenguaje. Los "personajes", tanto en su narrativa como en el teatro, han sido arrojados en las palabras mismas; es así como, por ejemplo, rechaza tajantemente ser vinculado al denominado teatro del absurdo. Aunque la filosofía y la literatura existencialistas favorecieron en algún grado el interés por la obra de Beckett en sus difíciles comienzos, lo cierto es que este se distancia de cualquier lectura que le atribuya a su obra una tesis sobre la existencia humana.

Los valores morales ya no son accesibles. Y no es posible definirlos. (...) Por eso nunca he estado de acuerdo con esa noción de teatro del absurdo, porque ése es un juicio de valor. Ni siquiera se puede hablar de la verdad que forma parte de la desazón. Paradójicamente, es en la forma donde el artista puede encontrar una solución de alguna clase. Se trata de dar forma a lo informe. Probablemente sólo en ese sentido podría existir una especie de afirmación subyacente (Cronin 523). 
El carácter "filosófico" de la obra de Beckett, esto es, el irrenunciable presentimiento de que hay en su escritura una concepción acerca del sentido -o sin sentido- de la existencia humana, enviaría al lector hacia un pesimismo radical. Esto es precisamente lo que Beckett pone en cuestión según el pasaje recién citado. Un juicio sobre la existencia implicaría una descarnada lucidez y autoconciencia acerca de la inanidad de esa existencia, pero el escritor irlandés insiste en que "no estamos en posición de juzgar nada" (Cronin 478). Esta imposibilidad de juzgar, de afirmar, ha de ser tenida como una clave fundamental de lectura de su obra, no para sancionar a priori la impertinencia de la cuestión de sentido, sino, por el contrario, para reflexionar la forma en que Beckett aborda de manera constante y obsesiva dicho asunto.

El malentendido de intentar comprender la escritura de Beckett como si hubiese implícita en ésta algún tipo de tesis filosófica (relacionada con nociones tales como las de "sin sentido" y "desesperanza") se debe al supuesto de que la imposibilidad de acceder al sentido de la existencia es un hecho del cual el hombre podría llegar a tener propiamente conciencia. Como si fuera posible al hombre actuar a partir de ese hecho; como si el "absurdo" pudiese ser un antecedente para las acciones humanas en su dimensión moral. Pero este es precisamente el problema, a saber, que lo que se denomina como ausencia de sentido es algo de tal magnitud, que no podría llegar a ser un tipo de saber o contenido de conciencia para el hombre. De aquí que sea un riesgo suponer que de las obras de Beckett es posible aprender algo. Pero, "el vicio interpretativo es muy fuerte y difícil de quitar" (Félix de Azúa 21). En efecto, ¿es posible leer sin interpretar? ¿Es posible comprender sin interpretar? ¿Es posible leer sin comprender? Esta última es probablemente una de las preguntas que la escritura de Beckett nos encarga: "Beckett no es difícil de 'entender', a pesar de la inconexa apariencia de su prosa, pero exige que el lector abandone su soberbia de lector (de otros libros) y se deje llevar por la nariz" (Félix de Azúa 15-16).

La supuesta "oscuridad" de la obra de Beckett, el carácter "impenetrable" y "enigmático" de su escritura, tendría que ver con la puesta en obra de la ausencia de sentido, antes que con su simple negación, porque dicha ausencia opera precisamente como lugar del sentido. Beckett nos conduce hacia aquella dimensión de la existencia en la que no se echa en falta un sentido trascendente. Se trata, en último término, de que el sentido no es un contenido que pueda ser aprehendido por la conciencia, entonces emerge su ausencia -su lugar (vacante)- ahí en donde se pregunta por él; el sentido es puesto en falta por la pregunta misma que lo demanda. En consecuencia, el 
tipo de conciencia que podemos atribuir a los "personajes" de Beckett se ha constituido en una dirección exactamente contrapuesta al proceso que describe la autoconciencia filosófica: "una crítica que pretendiera describir el nivel semántico [de un texto que rechaza definir las preferencias de su autor (...)] tendría que empezar reconociendo su imposibilidad, y acabar cartografiando los movimientos textuales que no le permiten ejercerse" (Asensi 26).

La escritura de Beckett no busca radicalizar la expresión de un sentimiento de soledad o aburrimiento, sino que, al contrario, es una forma de trascender la inanidad de la existencia. Más aún, la soledad y el aburrimiento devienen ellas mismas motivos de trascendencia que se contraponen al carácter trascendente del sentido como contenido. De lo que se trataría, en último término, en la escritura de Beckett es de trascender la opacidad de los contenidos trascendentes de conciencia. Es precisamente la expectativa o promesa de trascendencia generada por dichos contenidos lo que en la obra de Beckett queda puesto en cuestión. Sostenemos que la relación de la obra de Beckett con la filosofía tiene que ver con las operaciones autorreflexivas de ésta, antes que con determinados "temas". Ciertamente, como sugiere Peters Fifield: "At its most basic, Beckett's fitness for philosophical reading is surely a consequence of his works' concern with the same sort of fundamental ideas and experiences addressed by philosophy" (Fifield 149). A este respecto, suelen destacarse ciertas obras: Cómo es, Esperando a Godot, Días felices, Fin de partida, entre otras. Sin embargo, cabe preguntarse si la relación de la obra de Beckett con la filosofía es una cuestión temática o más bien de forma. Relacionado con esto, una filosofía especialmente relevante ha sido la de Descartes: una progresiva suspensión de la gravedad del mundo en su prepotente anterioridad. Lo que en Descartes es la disciplina del método, en Beckett corresponde a su escritura, que procede deshaciendo de mundo el lenguaje.

¿Qué sucede en la obra de Beckett respecto a la relación del sujeto con el mundo? ¿Se encuentra este inmerso de modo irreductible en la existencia de todos los días o, por el contrario, sus personajes son extra-vagantes en relación al orden cotidiano de las cosas? ¿Están sus personajes abrumados por la cotidianeidad o más bien desesperan debido a la total ausencia de ésta? ¿Se encuentran "adentro" de un lugar, buscando una salida, o más bien "afuera", intentando ingresar a algún lugar?

El motivo de la progresiva desposesión tiene en Beckett el sentido de ahondar en una experiencia radical de la cotidianeidad. En cierto modo, sus personajes están "afuera" pues carecen de un mundo en el cual poder 
orientarse y vivir normalmente, porque hasta las acciones u objetivos más simples demandan de ellos enormes tareas físicas y reflexivas. En efecto, es la forma en que los personajes asumen las tareas rutinarias de su existencia, lo que hace de ésta un enorme problema a resolver. Es así como el sujeto se encuentra en el corazón mismo de la cotidianeidad. Podemos examinar esta hipótesis en la trilogía narrativa Molloy (1951), Malone muere (1951) y El innombrable (1953). Un motivo que traza conceptualmente el itinerario que describen estas tres novelas es el de la imposibilidad. En la primera novela, Molloy es un sujeto que vive ahora en el cuarto de su madre. Comienza a relatar un viaje que realizó hace tiempo para llegar hasta donde se encuentra su madre, pero, aunque resulta totalmente improbable que pueda lograr comunicarse con ella (una anciana ciega, sorda, muda y prácticamente sin memoria), nunca llega a encontrarla. Todo indica que en el presente de la narración la madre ha muerto. En la segunda parte de la novela un tal Moran, un investigador al que le han encargado dar con el paradero de Molloy, emprende un viaje con su hijo para cumplir la tarea encomendada, pero finalmente, después de una serie de inexplicables incidentes, regresa a su casa sin haber dado con Molloy. En la última frase de la historia, Moran parece ingresar en la locura o en la literatura. En la segunda novela, Malone es alguien que se encuentra internado en un asilo (no sabemos con certeza si se trata de un asilo de ancianos, de dementes o de minusválidos), esperando la muerte. A lo largo de la novela Malone va contando historias para pasar el tiempo. Hacia el final, el monólogo da cuenta de una casi total pérdida del mundo, al punto de no ser ya capaz de reconocer siquiera los sonidos propiamente humanos. En la tercera novela, el innombrable es solo una voz que no cesa de hablar, o de pensar pues ambas acciones -hablar y pensar-, se han vuelto idénticas. En El innombrable la imposibilidad consiste en una voz que lo es todo, haciendo imposible el silencio. La imposibilidad de acabar algo -una tarea, un propósito, la certeza de un recuerdo, etcétera- ha devenido al cabo de la trilogía en la imposibilidad de terminarse y conquistar el silencio.

\section{LA INMOVILIDAD, CONDICIÓN DE LA IMPOSIBILIDAD.}

Suele destacarse como recurrente en la obra de Beckett -tanto en su narrativa como en el teatro- el tema de la inmovilidad a la que son progresivamente sometidos sus personajes. En la trilogía que aquí analizamos ese motivo es plenamente reconocible, y podemos considerarlo como un recurso, tanto en 
lo narrativo como en lo formal, destinado a poner en obra el motivo de la imposibilidad. Ahora bien, paradójicamente la imposibilidad es en Beckett una especie de telos en el devenir de sus personajes, un estado final al que quisieran poder llegar. Pero no se trata de un lugar hacia la cual hubiese que desplazarse o de una condición por conquistar mediante ciertas acciones, sino que el acceso a la imposibilidad es la inmovilidad: "en mí siempre ha habido -dice Molloy-, entre otros, dos payasos, el que sólo aspira a quedarse donde está y el que imagina que un poco más lejos se encontraría mejor" (Molloy 57-58). Lo más difícil es poder simplemente quedarse donde se está, porque el sujeto siempre imagina lejos otro lugar mejor, y acaso en esto consista la condición pensante del sujeto: imaginar(se) otros lugares que no son este en el que se encuentra. Más adelante Molloy vuelve sobre el asunto: "parece que hay dos maneras de comportarse en presencia de los deseos, la activa y la contemplativa, y aunque las dos vengan a dar el mismo resultado, mis preferencias, supongo que por una cuestión de temperamento, se inclinaban hacia la segunda" (Molloy 61-62). El problema no consiste en la simple oposición entre la acción y la contemplación y la necesidad de optar por una, pues la primera es siempre motivada por un tipo de pensamiento que en algún momento contempla, esto es, evalúa, examina, valora y finalmente decide. Por lo tanto, aquello a lo que Molloy se refiere como "quedarse donde está" ha de consistir en un modo del pensamiento que no signifique a la vez un tipo de decisión, de valoración o de afirmación. Es decir, si el primer payaso aspira a quedarse donde está, ello no se debe a que piense que es aquí "donde mejor podría estar", sino que es más bien alguien que no llega a inquietarse por saber en dónde podría estar mejor. ¿Qué clase de pensamiento habría de ser ese que, sin dejar de ser pensamiento, no alcanza a pensar más allá? En la segunda parte de Molloy, encontramos un pasaje que refiere centralmente el punto. Moran reflexiona sobre las bondades que podría traerle una parálisis local e indolora:

no me sorprendería mucho que las grandes parálisis clásicas contuvieran satisfacciones análogas y quizá más arrebatadoras [que la parálisis local e indolora]. ¡Hallarse por fin realmente en la imposibilidad de moverse! ¡Ahí es nada! Se me derrite de gusto el espíritu sólo con pensarlo. ¡Y además una afasia completa! ¡Y quizás una sordera total! ¡Y a lo mejor una parálisis de la retina! ¡Y probablemente pérdida de la memoria! ¡Y sólo con el mínimo de cerebro intacto [juste assez de cerveau resté intact] necesario para estallar de júbilo! Y para temer a la muerte como a un segundo nacimiento (Molloy 169). 
La idea de que a esa inmovilidad total habría de corresponderle un "mínimo de cerebro intacto", resulta esencial para comprender el hecho de que en los personajes de Beckett la inmovilidad es una condición de la imposibilidad y no su simple causa directa. En efecto, la imposibilidad no es aquí una situación particular a la que se ha sometido el cuerpo de un personaje, sino una circunstancia del pensamiento. Detengámonos en este punto.

Cuando se considera a esos personajes como concretamente "imposibilitados" -de hablar, de desplazarse, de comprender, de recordar-, se impone la representación de la inmovilidad (se trataría de algo que está realmente sucediendo allí, al interior de la ficción), y entonces su recepción impone preguntarse por el sentido de dicha representación, al modo en que se pregunta por el sentido de una imagen. El lector de Beckett se pregunta qué es lo que ha querido decir el autor con esa representación, y por lo tanto la circunstancia de imposibilidad es tomada como una metáfora o alegoría al servicio de la "puesta en escena" de una idea por la cual cabe interrogarse para acceder en cada caso al significado de la obra. Suele seguirse de esto la tesis de un pesimismo desolador sobre la existencia humana, atribuido incluso a una suerte de obsesión del autor. Por ejemplo, acerca de Fin de partida, el crítico inglés T.C. Worsley escribió: "la desolación de la obra no era la desolación del mundo, sino la de un espíritu individual" (Cronin 493), el de Beckett. Ponemos en cuestión precisamente aquella opinión según la cual la escritura de Beckett expresaría su manera personal de ver el mundo. No suponemos él tuviese en verdad una visión muy diferente sobre la condición humana, pero nuestra hipótesis es que en su escritura se ponen en operación circunstancias del pensamiento, antes que contenidos especulativos.

Volvamos a la noción beckettiana de un "mínimo de cerebro intacto" que sobrevive en la inmovilidad total. Se trata de un sujeto para el cual ya nada es posible, excepto seguir pensando. Pero, ¿en qué piensa un sujeto sometido a esa casi absoluta imposibilidad, en la que incluso el lamento ha sido erradicado? ¿Cómo opera un "mínimo de cerebro"? La dificultad está en determinar ese mínimo, que no ha de confundirse con la terrible experiencia que sería la actividad pensante en un cuerpo inmovilizado ni tampoco la actividad reflexiva de un cerebro materialmente atrofiado. Es posible definir ese mínimo como el ejercicio de un pensamiento que ha suspendido casi toda relación con la realidad del mundo. No hablamos, por lo tanto, de un pensamiento él mismo limitado o dañado, sino que, al contrario, encontrándose inhibida su raigambre en el cuerpo (como sujeto de un cuerpo), el pensamiento se entrega a sus solas fuerzas, las que se despliegan en el acotado dominio de un 
inquisidor que (se) interroga sostenidamente por una cotidianeidad ausente. Como muy acertadamente se ha señalado: "cuando los 'monologadores' de Beckett (...) se sienten incapaces de distinguir lo real de lo imaginario, continúan conservando la conciencia de sus dos interpretaciones posibles. Están gravemente perturbados por la visión crecientemente fluida del mundo real al que se adhieren con tenacidad" (Boisdeffre-Freidmann 39). Es decir, no solo el pensamiento, como resto de reflexividad en el sujeto progresivamente inmovilizado, sigue demandando un mundo, sino que solo se debe a ese afán, se agota por entero en ese requerimiento cartesiano, comprometiendo todo su potencial especulativo - e incluso metafísico- en lo que pareciera ser la cotidianeidad más intrascendente.

El motivo que recorre la escritura de Beckett en la trilogía no es solo el acabamiento, el itinerario de lo exhausto, sino el de un camino hacia la imposibilidad. Este es el verdadero desenlace de la descomposición. En este sentido, el cuerpo en Beckett es el medio de la progresiva catástrofe del sujeto, pero lo medular de este proceso consiste en plantear la cuestión acerca de lo que queda cuando ya nada queda. De aquí entonces que todo lo relativo a la idea de fin queda comprendido en Beckett en la noción de resto, basura, residuo, detritus. Porque lo gravitante no es "el fin" a secas (por ejemplo, la muerte o la nada), sino más bien la imposibilidad del fin. ¿Cómo entender qué sea el fin aquí? La existencia de Macmann, uno de los protagonistas de las historias que Malone narra en Malone muere, la segunda novela de la trilogía, transcurre en la inmovilidad: "[Macmann] empezó a soñar con un país llano donde nunca más tendría que levantarse ni mantenerse de pie en equilibrio, primero sobre el pie derecho por ejemplo, después sobre el pie izquierdo, y donde podría ir y venir y de esta manera sobrevivir, como un enorme cilindro dotado de inteligencia y voluntad" (115). El pensamiento no es el vehículo del espíritu hacia un "más allá" en donde se espera encontrar el sentido de un "más acá" demasiado contingente, particular y azaroso, sino más bien la ensoñación de un pensamiento sin cuerpo. Malone es un anciano que, internado en un asilo, espera la muerte y entre tanto relata historias de muerte, en las que él mismo reconoce haber asesinado a seis hombres. En esa espera de su acabamiento, lo que ha quedado es una conciencia habitada por esas historias; la vida de este sujeto consiste, pues, en recordarlas / narrarlas. El lector sabe en todo momento que las historias a las que asiste tienen lugar en la cabeza de un anciano demente. Más tarde, en El innombrable, la conciencia ha terminado por reducirse a sí misma. La voz que transcurre en un ininterrumpido "vómito de palabrería" es en cada instante la propia 
conciencia impedida de abandonarse por un rato, imposibilitada de olvidarse de sí misma contando(se) las historias de otros. La condición para ello es precisamente la inmovilidad del cuerpo, que ha llegado a ser total:

aquí no puedo contar estrictamente más que con mi cuerpo, mi cuerpo incapaz del menor movimiento y cuyos mismos ojos ya no se pueden cerrar como hacían antes (...) para que descansara de ver y de no poder ver o simplemente para que me ayudaran a dormir, ni pueden volverse, ni bajarse, ni elevarse al cielo, sino que están obligados, centrados y desencajados, a quedar fijos en el corto pasillo que tienen delante, donde el $99 \%$ de las veces no ocurre nada [oú il ne se passe rien, 99\% du temps] (El innombrable 49).

El cuerpo parece alcanzar un grado cero allí en donde ha devenido completamente inmóvil y la conciencia queda entonces atada a ese cuerpo o, mejor dicho, capturada por el ahi del cuerpo. En El innombrable el asunto de la conciencia no deja de ser el cuerpo; éste se le impone a partir del hecho de que ella ya no es sujeto de "su" cuerpo. La relación sensible con las cosas se ha hecho de pronto ininterrumpida, la conciencia no puede ya regresar a sí misma; privada de la posibilidad de ensimismarse, existe alterada en un mundo en el que no ocurre casi nada. Tal vez ese casi sea exactamente la diferencia que hace todavía posible el estar de esta conciencia en el mundo, entre las cosas. El mínimo de la conciencia se define por el hecho de que toda la actividad especulativa de la mente se aboca ahora a examinar un universo eminentemente perceptual. El punto es que la fijación del sujeto a este universo no consiste solo en la imposibilidad de trascender el orden de la sensibilidad, sino propiamente en la inmovilidad del cuerpo. El ahí de la conciencia en los "monologadores" de Beckett está dado por la subsunción de la mente en el universo de los sentidos del cuerpo en una situación siempre concreta y acotada, lo que hace que ese ahi no sea propiamente un mundo, porque no constituye un horizonte de sentido.

En las tres novelas de la trilogía el narrador no sabe dónde está, ignora la naturaleza de ese "su" ahí. Al inicio de Molloy leemos: "Estoy en el cuarto de mi madre. Ahora soy yo quien vive aquí. No recuerdo cómo llegué. En una ambulancia, en todo caso en un vehículo. Me ayudaron. Yo solo no habría llegado nunca" (Molloy 7). El ahí de Molloy es, pues, el lugar de su madre muerta, aunque ignora cuándo habría sucedido eso: “¿Había muerto ya cuando llegué? ¿O murió más tarde? Muerta para enterrarla, quiero decir. No lo sé. A lo mejor no la han enterrado todavía. Sea como sea, soy yo el 
que estoy ahora en su cuarto. Duermo en su cama. Uso su vaso de noche. He ocupado su lugar. Cada vez debo de parecerme más a ella" (Molloy 8). Molloy ha retornado al lugar de la madre sin saber cómo, pero a la vez ésta ha cedido ese lugar con su muerte; Molloy ha regresado, pues, a la madre como lugar, pero se trata de la madre muerta como lugar. ¿No sería esta la forma más radical y dramática de clausurar el lugar de la madre en el mundo? La madre ha devenido un no-lugar, pero si Molloy habita ahora en este -ya casi sin poder moverse-, entonces el mundo entero se ha transformado en ese ahí como no-lugar. Lejos de ser este un lugar en donde Molloy se encuentra, corresponde más bien al espacio en donde viene a consumarse un proceso de pérdida de sí: "Al despertar no siempre me acuerdo de quién soy" (45). Resulta sin embargo fundamental el hecho de que esa pérdida de sí se refiere a la identidad antes que a la simple conciencia del "yo". Precisemos. Conserva el yo una cierta capacidad de echar en falta la propia identidad, y por lo tanto el "yo" se transforma en un modo de hablar acerca de sí mismo, de lo que le sucede. A propósito de Molloy, Asensi señala: "a un vacío denominativo en cuanto a la designación del mundo, en virtud del que el mundo desaparece, corresponde un vacío denominativo en cuanto al yo que habla y que acarrea la desaparición de ese yo" (Asensi 47-48). En efecto, la conciencia que en los personajes de Beckett se interroga acerca de su ser, carece de identidad (la propiedad de una biografía en la que se reconozca), pero no puede dejar de decir "yo", por lo tanto, se trata ante todo de la conciencia de esa falta, la que queda nombrada el significante "yo". Dicho de otra manera: cuando la conciencia del hablante dice: "no siempre me acuerdo quién soy", está implícito en ello la paradójica circunstancia de que "[yo] no me acuerdo quién soy [yo]". Por lo tanto, si soy el que echa en falta saber quién soy, entonces el yo no ha sido aniquilado, sino que se ha reducido a una función mínima: la conciencia de una posible carencia total de atributos.

\section{PENSAR: "EL ZUMBIDO DE UN INSECTO"}

Un mínimo de conciencia (como capacidad de darse cuenta) es requerido para que el hablante se percate de su empobrecida situación. Un irreductible casi salva al yo de lo que podría llegar a ser su completa aniquilación: "Ya no soy casi consciente de lo que hago, ni por qué, cada vez lo voy comprendiendo menos, ésta es la verdad, para qué iba a ocultarla y, ¿a quién?, ¿a ti, a quien nada oculto?" (Molloy 54). Las preguntas que el hablante se hace a sí mismo, 
interrogando por su identidad (su pasado, sus propósitos, sus relaciones con los demás), no son la expresión de alguien que desespera en la angustia, sino más bien de un yo cuya existencia transcurre en un inmutable afán de razonamiento. Lo que constatan los personajes, en el ininterrumpido monólogo al que se encuentran sometidas sus existencias, más allá de la falta de respuestas, es el hecho mismo del pensamiento que, carente de contenidos, ha devenido en una infatigable persistencia de las preguntas: “¿De qué se trataba entonces? Quizá de un fallo del entendimiento [D’un défaut de l'entendement peut etre], que sólo resonaba si era percutido varias veces, o, si se prefiere, que resonaba, pero a un nivel inferior al raciocinio, si es posible concebir tal cosa, y es posible concebir tal cosa, puesto que yo la concibo" (Molloy 59). Molloy concibe que razona "a un nivel inferior al raciocinio". ¿Qué significa esto? Razonar no es algo que Molloy realice, sino más bien algo que simplemente le sucede. Entonces la actividad de pensar se transforma en algo que es extraño al sujeto. No es la simple carencia de respuestas lo que somete a sus personajes a una existencia que nos parece con frecuencia insólita, sino el hecho mismo de las preguntas. En esa extrañeza emerge incluso una cierta materialidad de la actividad reflexiva: "las palabras que yo pronunciaba y que casi siempre debían estar en relación con un esfuerzo de la inteligencia, me parecían a menudo el zumbido de un insecto [d'un bourdonnement d'insecte]" (Molloy 59). Acaso este zumbido sea precisamente el sonido de ese esfuerzo de la inteligencia, un esfuerzo ajeno a la propia conciencia; se trataría, pues, de un trabajoso intento que el hablante no reconoce como suyo. La inteligencia llega a ser-se reduce a ser- solo un trabajo allí en donde ya no revela, no aclara ni responde nada. Por eso las palabras parecen llegar en última instancia desde otro lugar: "yo no me decía nada en absoluto, sino que oía un rumor, una mutación en el silencio, y le prestaba oídos, al modo de un animal que se estremece y finge estar muerto, supongo" (Molloy 106). El hablante piensa (intercepta) los pensamientos que vienen de otro.

El pensamiento se reduce en los personajes de Beckett a un mínimo de razonamiento, no siendo posible mediante este llegar a conquistar ninguna certeza respecto al mundo; sin embargo, ese resto de razón es suficiente para acusar recibo del pensamiento mismo. Moran, el investigador al que, en la segunda parte de Molloy, se le ha encargado la tarea de encontrar a Molloy, recibe las misiones que se le encomiendan a través de un mensajero cuyo nombre es Gaber. "Ser [Gaber (el portador de las tareas)] el único en poder leer su propia escritura, estar en la más completa ignorancia del sentido de 
sus encargos sin saberlo y ser incapaz de retenerlos durante más de algunos segundos son condiciones que rara vez se encuentran reunidas en un mismo individuo. Y eran, sin embargo, las que se exigían a nuestros mensajeros" (Molloy 129). En efecto, Gaber no comprende el sentido de los mensajes de los cuales es portador, pero los alcanza a comprender suficientemente como para ser portador de ellos y transmitirlos a sus destinatarios. ¿En qué consiste este mínimo de suficiencia racional? La cuestión resulta fundamental, pues Gaber no solo es mensajero a pesar de sus limitaciones, sino que éstas constituyen precisamente las características óptimas del mensajero. Este no llega a hacer suyo el contenido del mensaje, y la condición de esto es que no llega a comprender su sentido, lo cual hace de Gaber un mensajero perfecto. He aquí la esencia del mensajero: el mensaje no deja nada en este después de que ha sido entregado, porque nunca fue de él. Pero, ¿qué significa el hecho de tener pensamientos que son propios? ¿Cuál podría ser en este caso el sentido de la expresión "mis pensamientos"?

Aquella enajenación del pensamiento es un motivo medular en la segunda novela de la trilogía. El sujeto enajenado reflexiona el hecho de encontrarse en una cabeza, y esta reflexión es ella misma enajenante, pues comienza haciendo emerger la diferencia entre el yo y "su" lugar. Planteada radicalmente, la pregunta "¿dónde estoy?" conduce indefectiblemente hacia la pregunta “¿quién soy?”, pues la ausencia de un lugar propio o aquella duda respecto al mismo se impone de pronto como la esencia de la reflexión que busca autocomprenderse. Replegándose sobre sí mismo, el pensamiento llega a extrañarse de toda espacialidad, y a concebir la propia interioridad como un espacio: "poco a poco mi reducido espacio zumba [vrombit] de nuevo. Diréis que en mi cabeza, y en efecto con frecuencia creo estar en una cabeza [et il me semble souvent en effet que je suis dans une tete], que estas ocho, no, estas seis paredes son de hueso macizo, pero de ahí a decir que es mi propia cabeza, no, eso jamás. Una especie de aire circula en su interior, he debido decirlo, y cuando todo calla, lo oigo lanzarse contra los tabiques que lo rechazan naturalmente" (Malone muere 74-75). Si es el espacio lo que zumba "en mi cabeza", entonces es la cabeza lo que zumba, el sujeto está en una cabeza que zumba, una cabeza que piensa. El sujeto se encuentra en su propia interioridad acosado por el pensamiento, entonces no se puede replegar pensando, es decir, el pensamiento no parece ser ya un recurso del sujeto, pues lo que este quisiera es precisamente escabullirse del pensamiento: "En alguna parte de semejante confusión el pensamiento se encarniza, lejos también. También me busca, como desde siempre, allí en donde no estoy. Tampoco 
sabe ya calmarse. Estoy harto. Que vaya a otro con su rabia de agonizante" (Malone muere 18). El pensamiento pone al sujeto a preguntarse cosas, acaso a desear, a esperar, a recordar, a intentar saber quién se es: ¿quién es ese otro que el sujeto (ya) no es? Ese deseo de saber es parte de la enajenación en la que consiste ser puesto a pensar: "me siento preso de un extraño deseo de saber qué he hecho, por qué, y decirlo. Así llego al límite de lo que me propuse en mi juventud y me ha impedido vivir. En vísperas de ya no ser, llego a ser otro" (Malone muere 31). Con la expresión "extraño deseo" se hace referencia a la extrañeza que impregna al deseo de saber acerca de sí. Más precisamente, lo extraño es que esa relación del sujeto consigo mismo pueda consistir en un saber, con lo cual la identidad resulta desde su origen afectada por una diferencia que está hecha precisamente de saber. De aquí entonces el peculiar deseo de un no saber en el que podría consistir si no la identidad, al menos la tranquilidad de ser sin tener que pensar en ello. Molloy formula aquel estado que vendría a ser el reposo de la conciencia en la nada: "no saber nada no es nada, no querer saber nada tampoco, pero lo que es no poder saber nada, saber que no se puede saber nada, éste es el estado de la perfecta paz en el alma del negligente pesquisidor" (Molloy 76). Este saber acerca de la radical imposibilidad del saber traería la paz al "pesquisidor", el aquietamiento de las preguntas dado que no existe por qué ni a quién hacerlas.

Pero dicho saber es algo imposible pues implicaría la anulación de la conciencia. Esto define aquello a lo que Beckett se refiere en la escritura de Molloy con la expresión "olvido de ser", cuando la conciencia se funde con la densidad del mundo, disolviéndose la diferencia sujeto-objeto: "a veces no sólo me olvidaba de quién era, sino de que era, me olvidaba de ser. Entonces ya no era aquella caja herméticamente cerrada en la que debía haberme conservado tan bien, sino que descendía un tabique y yo me llenaba de raíces y tallos (...)" (Molloy 58). Este olvido sería una de las formas en que la conciencia cancela la diferencia interna que la constituye, acosada por las preguntas que empujan su relación con el ser: "dentro de la caja hay que ir con cuidado, plantearse preguntas, por ejemplo, si existimos aún y, caso de no existir, cuándo dejamos de existir y, caso de existir, cuánto tiempo vamos a durar todavía, cualquier cosa que sirva para que no perdamos el hilo del sueño" (Molloy 58). Otra forma en que la conciencia, sin superar aquella diferencia interna, logra aquietar el afán de saber y desoír las preguntas es cuando se entrega al silencio del mundo. En la primera novela de la trilogía el hablante es abordado por el silencio, sin saber si ese silencio es 
efectivamente el silencio del mundo o simplemente el hecho de no alcanzar a escuchar nada: "aunque a veces paso horas sin oír nada se debe a razones que ignoro, o porque quizá todo lo que me rodea se sume verdaderamente en el silencio, de vez en cuando, mientras que para los justos nunca cesa el mundanal ruido" (Molloy 35). Se trata nuevamente de una "incompetencia" del sujeto llevada al extremo en que llega a operar como generadora de realidad, cuando no se trata simplemente de que las cosas no emitan ruido, sino de que el silencio mismo podría ser acaso la materia de lo real. Moran reflexiona: "Ni una persona de cada cien sabe callarse y escuchar, ni siquiera lo que eso significa. Y sin embargo es entonces cuando se distingue, más allá del estrépito absurdo, el silencio de que está formado el universo" (Molloy 146). Lo que nos interesa señalar en este punto es que el tratamiento beckettiano de la conciencia del mundo no corresponde al de la filosofía existencialista ni a una estética nihilista.

La trilogía da cuenta del itinerario que sigue la conciencia hacia su definitivo agotamiento, pone en obra una especie de fenomenología de la autoconciencia, haciendo emerger las aporías de una conciencia que en el movimiento de autocomprensión (dándose a sí misma como "objeto") se dispone como el polo imposible de su intencionalidad reflexiva. Trasladando a la poética de Beckett el concepto fenomenológico de intencionalidad, diríamos que toda conciencia en la acción de ir contando una historia es esencialmente conciencia de sí misma. En el marco de esta cuestión, ¿qué puede ser el silencio? ¿Cómo opera el silencio? El silencio es el médium narrativo de la autoconciencia que ha ido más allá de la densidad del mundo: "el silencio por momentos es tal que la tierra parece estar deshabitada. (...) Basta no oír otra cosa, en su agujero, durante algunos días, que el ruido de las cosas, para que uno se crea el último superviviente del género humano" (Malone muere 125). Del silencio se habla, se escribe la conciencia que lo dice cuando las cosas ya no interfieren. La conciencia se habita a si misma como mundo. El silencio opera como la muerte imposible del hablante, pues este permanece cuando ya nada queda. En la segunda novela, el silencio es de alguna manera anunciado por el ruido progresivamente indiferenciado del mundo:

poco a poco los ruidos del mundo, tan distintos entre sí, y que tan bien sabía distinguir unos de otros, a fuerza quizá de ser siempre los mismos se han unido en uno solo, hasta convertirse en un solo zumbido continuo [qu'un seul grand bourdonnement continu]. (...) Los ruidos de la naturaleza, los de los hombres e incluso los míos, se mezclan en un único y desenfrenado galimatías (Malone muere 52). 
El momento del ruido es el ingreso del mundo - de las cosas del mundo-en la subjetividad autoconsciente, cuando escuchar una cosa se da a pensar al modo de un "creo haber oído algo", es decir, pienso que oigo. ¿Y si en verdad esos sonidos no correspondiesen a cosas que realmente suceden? Una autoconciencia exacerbada, obsesionada con la referencialidad de los sonidos, se enfrentará, tarde o temprano, a la posibilidad de cancelar esa referencia. De pronto cabe pensar que no existan las cosas que el hablante piensa que escucha: "Pero los ruidos, los pasos, que creo oír suben hacia mí, ¿lo hacen realmente? Nada, en verdad, permite afirmarlo. De ahí a deducir que son puras y simples alucinaciones hay un paso que sin embargo vacilo en dar" (Malone muere 71). Acaso este interés en establecer (en saber) si acaso los pensamientos corresponden efectivamente a estados de cosas, describe más bien una pérdida de interés por el mundo propiamente tal.

Finalmente, en El Innombrable, el silencio parece ser el espacio de los sonidos sin mundo que pueblan la interioridad alienada del monologador: "Esos millones de sonidos diversos, siempre los mismos, repitiéndose sin cesar, es lo único que se necesita para que se os forme una cabeza, al principio un botón, antes de volverse enorme, silencioso (...)" (El Innombrable 112). El pensamiento comienza a transformarse en un caótico bullicio y de esa manera el silencio se hace anunciar en la conciencia como la única posibilidad de lo por venir, aunque quizá ello no suceda nunca. Hacia el final de Malone muere, el hablante reflexiona: "me he vuelto a la larga quizás poco sensible a los sonidos específicamente humanos" (Malone muere 152). Los sonidos humanos pierden su especificidad, en correspondencia con la progresiva extrañeza de los pensamientos en la interioridad del sujeto. Esa indiferenciación de los sonidos es la prueba de que se avanza hacia el fin, aunque este no pueda llegar. Luego, en El Innombrable, el camino hacia el silencio, próximo a su desenlace, está dado por la indiferenciación de los propios pensamientos, cuando ya solo queda esa voz interior, a la que no se le entiende lo que dice: "Oírla siempre [a esa voz] sin oír lo que dice, es a lo que llamo callarme. (...) Oír demasiado mal para poder hablar, eso es mi silencio" (El Innombrable 158). No puedo oír(me), luego, no puedo hablar propiamente yo, cuando la actividad del pensamiento ya no puede consistir en otra cosa que en intentar dar conmigo, movido por la extraña prepotencia de las preguntas acerca de quién soy y dónde estoy. 


\section{LA ENAJENACIÓN DEL PENSAMIENTO}

La escritura de Beckett conduce al lector hacia dos regiones contrapuestas del vacío: lo abisma ante preguntas límite cuya sola formulación desfonda al sujeto (quién habla, acaso hay alguien más, cómo llegué aquí) o lo entrega al orden intrascendente de las cosas. Los personajes de Beckett -escribe Kenner- "siempre se sienten sorprendidos por las naderías que recuerdan; pero lo que permanece, sobre todo, es un claro sentido de una sintaxis declarativa, un sencillo pero adecuado vocabulario, y un gusto por los cálculos, y estas cosas, además de unos cuantos objetos, como piedras, zanahorias, una o dos bicicletas, un pedazo de cordel, son los ingredientes con los que opera la empresa narrativa de Beckett" (Kenner 124). Una mente radicalmente incompetente se deja sorprender ante el ahí de las cosas, poniendo en ejercicio una especie de obsesión analítica que la protege de cualquier distracción nihilista.

En un creciente distanciamiento del sujeto respecto al mundo, el pensamiento, lejos de transformarse en lo único que el hablante podría reconocer como propio, va deviniendo en algo extraño, como si se tratase de un hecho, de una acción, carente de todo orden: "Palabras e imágenes se arremolinan [tourbillonnent] en mi cabeza, surgen inagotables y se persiguen, se funden, se destruyen. Pero más allá de semejante tumulto la calma es inmensa, y también la indiferencia" (Malone muere 39). Asistimos aquí a una especie de escepticismo en que el yo es un "personaje" que (a diferencia de lo que ocurre, por ejemplo, en el discurso estrictamente filosófico del empirismo) vive en un mundo que se descompone en sonidos e imágenes cuya relación con una efectiva realidad solo puede ser asunto de preguntas y de conjeturas. Lo medular en este punto es que, a partir de esa incertidumbre fundamental, la inmediatez del hablante se hace extraña: "Contra las manos son las rodillas las que presionan, contra las rodillas las manos, pero ¿qué es lo que presiona contra las nalgas, contra las plantas de los pies? Lo ignoro" (El Innombrable 53). Se trata, pues, de la pregunta acerca del límite y de lo que presiona contra esos límites. Desde la espontánea actitud natural de la conciencia, el mundo viene siendo aquello que comienza allí en donde el yo termina, pero ¿con qué limita el yo? ¿Limita este realmente contra algo? No se trata solo de cuestiones que interrogan por lo otro que el yo, sino que ponen en juego la identidad misma del sujeto y la posibilidad de pensar a este de acuerdo a relaciones de propiedad: "hablando con exactitud, me es imposible saber, de un instante a otro, qué es mío y qué no lo es, según mi definición. (...) mis relaciones con la realidad son quizá muy lejanas" (Malone muere 122). Los 
límites no se van desdibujando hasta disolverse; por el contrario, la cuestión del límite se transforma en algo absolutamente fundamental, porque acaso lo único cierto es que hay un límite.

Una de las formas en que el límite como distancia con el mundo se da a experimentar en las primeras novelas de la trilogía, es en la incomprensión del lenguaje. Las preguntas, por ejemplo, parecen venir desde lejos: "Estoy tan acostumbrado a que no me pregunten nada que cuando me preguntan algo tardo un buen rato en comprender qué me preguntan" (Molloy 25). Las preguntas portan consigo la lejanía del mundo, e incluso se hacen sentir como ajenas al entendimiento. El problema aquí no es solo saber las respuestas, sino llegar a comprender las preguntas mismas, especialmente cuando las relaciones con los demás consisten en preguntas y respuestas. En la segunda novela de la trilogía, Macmann en el asilo pregunta a Lemuel, su enfermero, si acaso el lugar en el que se encuentran es un asilo público o privado, si recibe a viejos y lisiados o a locos y, finalmente, si acaso podrá salir de allí algún día: "Lemuel permanecía pensativo durante largo rato, diez o quince minutos, inmóvil o si se quiere rascándose la cabeza o la axila, como si tales preguntas no se las hubiera formulado nunca, o quizá pensando en otra cosa" (Malone muere 148). En Molloy y en Malone muere el hablante se encuentra de un lado del límite que lo separa del mundo y de los demás, encerrado en una habitación y contando historias para reparar así la ausencia de un mundo que ha devenido objeto de demasiadas conjeturas. En El Innombrable, en cambio, el hablante se ha desplazado hacia una interioridad que carece de toda relación con un afuera. Una exigencia interna a la lectura de la trilogía consiste en dar cuenta del hecho de que en El Innombrable la escritura ha llegado al límite de sus posibilidades, y en términos narrativos se ha extremado la relación "filosófica" del yo con los límites del mundo; esto es, la reflexión de la experiencia a partir de la figura de la autoconsciencia:

[ese lugar] del que no sabré nunca si me engulle o me vomita y que acaso no sea más que el interior de mi cráneo lejano [mon crane lontain], por donde yo erraba en otro tiempo, ahora estoy fijo, perdido de pequeñez, o empujando contra las paredes con mi cabeza, mis manos, mis pies, mi espalda, mi pecho, y siempre murmurando viejas historias, mi vieja historia, como por primera vez (El Innombrable 51).

Se trata de una especie de "ficción filosófica". Ocurre como si el sujeto empírico de la reflexión cartesiana se hubiese dejado conducir biográficamente por la duda, que iba devastando las fuentes de toda certeza posible, hasta arribar al 
Cogito ("pienso, luego existo") como fundamento de toda verdad posible. En El Innombrable el hablante se encuentra encerrado en su propio pensamiento o, más precisamente, en su habla. Se trata, por lo tanto, de un encierro inédito respecto a las novelas anteriores, debido a que se ha radicalizado tanto la experiencia del límite como la incertidumbre acerca de la naturaleza de éste. Por eso el hablante no sabe si el lugar en el que se encuentra "me engulle o me vomita". En esta novela, en el orden de su escritura, tiene lugar un desplazamiento esencial del pensamiento al habla. En las novelas anteriores, la concreta situación de aislamiento de la interioridad había sido el motivo de diversas conjeturas y suposiciones, en cambio ahora el innombrable piensa a veces que está encerrado, para darle límites espaciales a lo que está sucediendo: "A veces me digo que también yo estoy en una cabeza, es el temor lo que me lo hace decir, y el deseo de hallarme en seguridad, rodeado por todas partes de huesos espesos" (El Innombrable 108). ¿De qué naturaleza es el límite cuando el lugar de existencia del yo hablante es el habla?

En la última novela de la trilogía el habla misma es el desenlace. En cierto modo ya no existe un yo que piensa preguntándose acerca de sus relaciones con los demás y con las cosas, presa de un creciente escepticismo (como sucede en Murphy, publicada en 1938, probablemente la novela más propiamente cartesiana de Beckett). Ahora el yo está hecho de palabras: "soy palabras, estoy hecho de palabras, de palabras de los demás" (El Innombrable 149). El yo se ha diseminado en el lenguaje, en la proliferación de palabras que se suceden sin solución de continuidad y los límites se han evaporado en la insubordinada emergencia del orden significante. Sin embargo, la condición irreductible de la escritura en Beckett es, como lo hemos señalado anteriormente, la autoconciencia. Y es ésta la que hace necesario restituir una y otra vez la cuestión del límite como separación y distancia entre el yo y el no-yo. En efecto, el límite es algo de cuya naturaleza irreductible el yo es autoconsciente: "estoy yo, lo noto, sí, lo confieso, lo acepto, estoy yo, (...) estoy yo, de una parte, y ese ruido, de otra" (El Innombrable 152). Entonces el asunto de la novela es la imposibilidad de llegar a fin. Por cierto, al cabo del recorrido se podrá concluir que el fin nunca fue posible, y que por lo tanto Molloy no está ni más cerca ni más lejos del fin de lo que lo estaría el innombrable. Esto sería correcto, si de "personajes" e "historias" se tratara, pero ¿se trata solo de eso?

¿Cómo es que la imposibilidad del fin puede ser el desenlace de un itinerario narrativo, el de la trilogía? ¿Cómo pensar el hecho de una escritura -la de Beckett- que se conduce formalmente hacia esa imposibilidad? A partir de 
estas cuestiones conjeturamos que la imposibilidad no describe un determinado estado de cosas ni una condición de la existencia humana. No hay en Beckett, como hemos señalado, un diagnóstico moral o una tesis filosófica sobre lo humano, sino el desarrollo de una escritura cuyo efecto devastador consiste en un paradójico despoblamiento de la mente por acción de la autoconsciencia. Lo que queda al final es solo el yo, en la soledad y el silencio; pero la queda del yo lo es de la posibilidad de decir "yo". Entonces se habrán de restituir, inmediatamente, el presentimiento del mundo y el ruido del pensamiento: "él siempre dice yo, como si fuera yo" (El Innombrable 170).

\section{LO QUE AL FINAL QUEDA ES TODO}

Ya hemos atendido al inicio de Molloy, reflexionando la figura de ese hablante que se encuentra en la que supone es la casa de su madre, en su dormitorio, sin saber cómo llegó hasta ese lugar. La segunda parte de la novela se inicia con el relato de Moran: "Es medianoche. La lluvia azota los cristales. Estoy tranquilo. Todo duerme". La historia de Moran termina con el siguiente pasaje:

Yo vivía en el jardín. Ya he hablado de una voz que me decía esto y lo otro. En aquella época comenzaba a actuar de acuerdo con ella, a comprender sus deseos. No se servía de las palabras que habían enseñado al pequeño Moran, quien a su vez las había enseñado a su pequeño. De modo que al principio no sabía lo que quería. Pero he terminado por comprender su lenguaje. (...) quizás erróneamente. (...) Entonces, entré en casa y escribí, es medianoche. La lluvia azota los cristales. No era medianoche. No llovía (Molloy 211).

¿De quién es esa voz "que me decía esto y lo otro”? ¿Es acaso la voz del escritor? ¿La voz de Beckett? Hemos seguido la escritura de alguien que actuaba guiado por una voz cuyos deseos recién comienza a comprender; es la voz que dicta ese texto en la conciencia. Ahora esta escribe que escribe lo que esa voz le venía dictando, añadiendo al final que lo que escribe no es lo que sucede ("No era medianoche. No llovía").

En el inicio de Malone muere, el hablante no sabe-no recuerda-cómo ha llegado hasta allí: "Jamás he logrado precisar, para hacer de él un punto de partida, el último recuerdo anterior a mi despertar aquí" (Malone muere 14); más adelante precisa que hubo un tiempo anterior al hecho de encontrarse en ese lugar: "Debo decir que no sé cuánto tiempo llevo aquí. Sé únicamente que 
era ya muy viejo antes de llegar" (Malone muere 17). Malone está esperando la muerte, está aguardando el fin, pero la muerte nunca llegará a él pues la conciencia no puede ser contemporánea de su propio fin, no puede dar testimonio de su definitivo acabamiento. El sujeto es una conciencia que no puede dejar de hablar: "no tengo por qué reflexionar, ni antes ni después, sólo abrir la boca para que dé testimonio de mi vieja historia y del largo silencio que me ha vuelto, de modo que todo transcurre en medio de un gran silencio. Y si alguna vez me callo es que no habrá nada que decir, aunque no se haya dicho todo, aunque no se haya dicho nada" (Malone muere 98-99). ¿Cómo podría no quedar nada por decir cuando "no se ha dicho todo" o si incluso "no se ha dicho nada"? ¿Acaso cuando alguien dice, no dice siempre algo? En suma, ¿cuál es el asunto del decir si cabe la posibilidad de que, después de todo, nada haya sido dicho? Paul Stewart ha señalado la importancia del tratamiento de la temporalidad en la producción de la conciencia narrativa: "Molloy's difficulties begin with beginning; the Unnamable's begin with disjunction before beginning, for the ontological inquiry and desesperation of the Unnamable go beyond and before the question of 'I, say I' and believing it" (Stewart 136). Es decir, en El Innombrable la temporalidad ha ingresado en la conciencia, de manera que ya no es posible simplemente "contar una historia", no es posible a la voz trascender el tiempo que fluye con su propia performance lingüística.

El fluir de las palabras en El Innombrable da cuenta de un habla sin asunto. En efecto, como en las primeras dos novelas de la trilogía, el hablante comienza aquí expresando una radical incertidumbre respecto a su situación, pero ahora parece tener plena conciencia de que el pasado ha desaparecido completamente de su mente. Lejos el de sumirse la conciencia en un presente absoluto, la falta de memoria -que se da con una paradójica memoria de la pura falta-subraya el principio de la anterioridad. Es forzoso suponer un comienzo, como si la idea de una existencia increada fuese algo reñido con la razón, aunque ello no supera el hecho de ser un supuesto: "debo suponer un comienzo a mi estancia aquí, aunque sólo fuera para comodidad del relato. El infierno mismo, aunque eterno, data de la rebelión de lucifer" ( $E l$ Innombrable 43). La posibilidad de hablar de algo exige pensar un inicio de habla, pero en sentido estricto de lo que se trata es del comienzo del hablante mismo en tanto que hablante (aquel que, hablando, comenzó).

Quien habla no solo ha comenzado a hablar, sino que él mismo habría comenzado a existir en algún tiempo, lo que en este caso significa que ha comenzado a estar. Sin embargo, en el caso del innombrable, cuya existencia 
se define por la condición de hablante, haber comenzado a estar-existir no es sino haber comenzado a hablar; en cierto modo, ha estado hablando "desde siempre" y, por lo tanto, su actual condición nunca tuvo un comienzo. He aquí lo medular de la cuestión. Es forzoso suponer que quien habla, ha comenzado a hablar en un instante determinado, se pone entonces un yo cuya existencia trasciende al habla. En efecto, esencial a esta cuestión es la imposibilidad de pensar la absoluta co-incidencia entre el inicio del yo y el comienzo del habla, porque incluso en la comprensión que el hablante tiene de su propia actividad parlante, el yo habría de ser el subjectum que pre-existe al habla: “¿Dónde ahora? ¿Cuándo ahora? ¿Quién ahora? Sin preguntármelo. Decir yo. Sin pensarlo" (El Innombrable 37). Lo efectivamente impensable es que el yo haya comenzado a existir hablando, pues esto pone en cuestión la originaria identidad logocéntrica del yo. La esencia de la vida yoica consistiría en pensar, pero se trata siempre de los pensamientos de alguien al que esa actividad -pensar- constituye; por lo tanto, es esencial al yo reconocer en todo momento esos pensamientos como mis pensamientos. La vida del yo comienza hablándose a sí mismo, mas no consigo mismo (como en un diálogo), sino que quien dice "yo" escucha sus pensamientos, sabe lo que piensa, y es precisamente esta relación consigo mismo desde el origen lo que instala como por debajo de quien dice "yo" la fuente de esos sus pensamientos. No se trata en sentido estricto de "otro yo", porque de hecho en la expresión "yo" se identifica el objeto referido por el pronombre con el agente concreto de la enunciación. Pero la posibilidad de la enunciación misma implica una diferencia alojada en el seno de esa identidad, nos sugiere la existencia de un ello que piensa (el innombrable), quedando así la existencia del yo remitida al orden de la enunciación.

Beckett "repite" en cierto modo el itinerario que hace Descartes en la Meditaciones Metafísicas, cuando este se dirige hacia el yo del pensamiento mediante la puesta en duda de todas las opiniones hasta ese momento tenidas por verdaderas. Pero si Descartes retrocede desde el mundo pre-dado hacia un yo puro al que denominará "una cosa que piensa", Beckett en cambio se dirige hacia el origen de las palabras que se dicen (que se oyen en la intimidad de la conciencia) con la pregunta ¿quién habla? Como señala Richard Begam: "If Malone Dies carries us to the end of the book, The Unnamable offers us our first glimpse of what lies beyond: the beginning of writing" (Begam 155). El yo que habla es el lugar de la desposesión, y esto es lo que habrá de conducir al lector hacia la escritura, más precisamente hacia el inicio de ésta como el fin del sujeto. Porque el hablante es quien dice las palabras, pero 
señala en más de un lugar que las palabras son de otros. ¿Qué significa esto? En El Innombrable la inmovilidad del hablante se relaciona con el hecho de que carece de un pasado; no existe un relato de cómo llegó hasta donde se encuentra en el presente. Es decir, el hablante no sabe, no es sujeto de "su" saber. Entonces "las palabras son de otros" porque traen consigo un saber que no es de quien ahora habla, sino que fue introducido en este mediante el aprendizaje de esas palabras; fue así como un mundo ingresó en el hablante. Así también le fue transmitido su origen, el cómo de su propia llegada a la existencia: “¿Es concebible, por ejemplo, un conocimiento innato de mi madre? No para mí. Fueron esos señores los que me hablaron de ella. (...) Igualmente me pusieron al tanto de Dios. Me dijeron que procedo de él en última instancia" (El Innombrable 45). Constatamos, una vez más, la relación entre el tratamiento beckettiano de la subjetividad y el escepticismo cartesiano, solo que, a diferencia de lo que ocurre en la meditación propiamente filosófica, en la escritura de Beckett el progresivo despoblamiento de la mente del ego biográfico no es un recurso reflexivo en la exposición, sino el itinerario del hablante conduciéndose en la escritura hacia su propio origen. En este se encontraría la escena de un saber, de un aprendizaje conformador de mundo en compañía de los demás, el germen de la intersubjetividad como condición de la realidad: "sobre todo era a mis semejantes quienes me querían hacer tragar. Ponían en ello un celo y una obstinación increíbles. No me acuerdo nada de aquellas conversaciones. No debí entender gran cosa. Me daban cursos sobre el amor, sobre la inteligencia, precioso, precioso" (El Innombrable 45). En efecto, la subjetividad ingresa en la realidad de un mundo común aprendiendo a valorar aquello que definiría a lo humano en su dignidad; de aquí el sentido de esos "cursos sobre el amor, sobre la inteligencia". En El innombrable el hablante no rechaza esos valores, no tiene una idea diferente acerca de lo que sean la realidad y los hombres que habitan en ella, sino que simplemente no entiende. Esto es lo que comienza a horadar poderosa e irreversiblemente la conciencia del mundo, el espacio doméstico, la disponibilidad instrumental de las cosas, las relaciones con los demás. Es así, no entendiendo, como los personajes de Beckett (Watt, Murphy, Molloy, Malone) inician el proceso de su patética deshumanización.

¿Qué significa no entender? ¿Qué sucede cuando no se entiende? La mente se enfrenta a las palabras como materialidad de significantes muertos; más aún, la mente se descubre a sí misma atareada por palabras que no cesan de ser habladas en su intrascendencia. En Descartes el no saber (cuando las opiniones acerca de las cosas han devenido dudosas o dudables) deja lugar al vacío del 
ego puro; en cambio en Beckett el no saber opera como no entender. En la tercera novela de la trilogía, la narrativa de Beckett dará un paso más hacia la escritura como tal; más precisamente: hacia la imposibilidad de clausurar el yo en la escritura, como escritura.

La corriente de la conciencia ya no intenta infructuosamente alcanzar la realidad mediante las palabras, sino que se dirige hacia el origen mismo de estas, en la conciencia. Entonces la voz de la conciencia se vuelve otra, porque las palabras, habladas sin cesar, oponen su opacidad y entonces la conciencia misma deviene una voz. Cuando esto ocurre, ya no será necesario precisar que se trata de una voz otra o de la voz de otro; la conciencia se vacía en una voz, la "identidad" usurpada por un hablante ha devenido la conciencia de otro o acaso la conciencia misma como eso otro que piensa, que habla.

Siempre me gustó no saber, pero Mahood me decía que no estaba bien. Él tampoco sabía nada, pero eso le atormentaba. Es su voz la que a menudo, siempre, se ha mezclado con la mía, hasta el punto de cubrirla a veces por entero, hasta el día en que me abandonó de veras o en que ya no quiso abandonarme. (...) Durante sus ausencias (...) su voz seguía dando fe de él, como tejida con la mía, impidiéndome decir quién era yo, lo que yo era, a fin de poder callarme, de no oír más (59).

"Mahood" es el nombre de la voz, pero es también el nombre que el hablante da a su propia conciencia parlante. Al identificarse la voz de la conciencia del hablante con la voz que habla en él, la escritura de Beckett da cuenta de la paradójica identidad del yo -esa que se hace sentir en la enunciación del pronombre "yo"- estableciendo una diferencia en el seno de aquel supuesto sujeto cuyo núcleo indivisible quisiera nombrar. Entonces el hablante no puede llegar a nombrarse, pues eso que nombra se retira una y otra vez hacia la sombra de lo en-sí como un algo innombrable (una cosa) o, por el contrario, comparece para-sí, pero como alguien que permanece innombrado porque ha recibido un nombre ajeno al haber sido nombrado por otro. Al final, el yo se devela como un extraño en un universo de palabras: "nadie sabrá nunca lo que soy, nadie me lo oirá decir, aunque lo diga, y no lo diré, no podría, pues no tengo más que el lenguaje de ellos" (78).

Es cierto que Beckett lleva a cabo un trabajo de agotamiento del lenguaje, pero esto no constituye un fin en sí mismo, prueba de ello es el hecho de que tal agotamiento no llega a ser nunca del todo alcanzado. Siendo el ejercicio del agotamiento la imposibilidad que anima su escritura, cabe preguntarse por 
el asunto último de esa gimnasia del lenguaje, que se sostiene y progresa en el agotamiento escritural del significado. ¿Cuál es el objeto de una fidelidad que nunca llegará a pleno cumplimiento, sino que se propone como un proceso que se sabe de antemano condenado al fracaso y en donde la única satisfacción será la de haber hecho todo lo posible?

Hacia el final de El innombrable: "todo debe estar dicho [tout doit etre dit], pero no ha llegado mi turno de saber qué, de saber quién soy, dónde estoy, y cómo hacer para no ser más, para no estar más ahí" (180). La esperanza de llegar el hablante a nombrarse a sí mismo en propiedad se fundaba en las posibilidades aparentemente infinitas del lenguaje, en que el sujeto de la enunciación no podía dejar de recurrir una y otra vez al sujeto del enunciado para alienarse en este y dejarse decir, y entonces disponer de un nombre y de una historia. El telos de esa esperanza no era sino el cumplimiento de la identidad entre el sujeto del enunciado y el de la enunciación. Pero esa diferencia es la condición misma del lenguaje, Ahora que, según leemos al final de la trilogía, ya todo habría sido dicho, el "yo" de la enunciación sobrevive a los enunciados cuyos sujetos se marchitan ahora como significantes cadáveres: "nunca hubo nadie, nunca hubo nada, nadie más que yo, nada más que yo, hablándome de mí, imposible detenerme, imposible seguir, pero debo seguir, voy, pues, a seguir, sin nadie, sin nada más que yo, que mi voz mía (...)" (160). El hablante constata que es imposible detenerse, porque constituirse ininterrumpidamente en sujeto de enunciados -aunque sea diciendo las palabras "de otros"- es la única posibilidad de tener noticia de la propia existencia (hablo, luego, existo). Pero, a la vez, es imposible seguir, porque al cabo de la trilogía el yo ha devenido en una especie de hablante puro, una autoconciencia plena tanto acerca del habla misma (la acción que la sostiene en la conciencia) como de la intrascendencia de las palabras. Entonces permanecer hablando no significa avanzar hacia alguna parte.

La afirmación de que todo ya ha sido dicho se inscribe en el orden de la ficción; es decir, en El innombrable como novela Beckett puso en escena el habla ininterrumpida mediante la cual algo se pregunta si acaso es posible escuchar en ello una voz. Porque la cuestión de si acaso las palabras llegan a significar algo realmente, se subordina a la pregunta de si existe alguien que ha querido decir o hacer algo con ellas. Es cierto, como señala José García Landa, que aquí "lo importante no es la identidad del narrador: así, las interpretaciones que nos dicen que es el monólogo de un demente, o los pensamientos de un alma en el más allá, etc., no son suficientes. Lo importante en esta novela es su proceder, su manera de volverla significación contra sí misma" (García Landa 
77). Sin embargo, el asunto de la novela es precisamente la cuestión acerca de "la identidad del narrador", claro está que considerada como un recurso de la escritura. ¿Por qué? ¿Qué privilegio tiene este asunto para el trabajo escritural de agotar la significación? La voz del narrador no dice que la significación ha llegado a su término, esto no es un acontecimiento propiamente narrativo (pues si así fuera, la escritura terminaría por subordinarse a la literatura), sino que el habla del innombrable ha terminado por develar su falta de asunto. He aquí la diferencia fundamental con la idea existencialista del absurdo; más aún, su diferencia con la filosofía. A propósito de La náusea de Sartre, Kontantinovic escribe: "Morir es la muerte del significado. En toda muerte se muere la señal y vuelve la cosa, aquella tras la cual no hay nada, que está encerrada consigo misma" (Konstantinovic 130). En Beckett, por el contrario, la muerte del significado es la agonía infinita de la señal, porque los signos no cesan de enviarnos hacia donde ya no hay nada. He aquí el acaecer de la más absoluta inmovilidad. La voz permanecerá hablando, sabiendo que ya nada puede esperarse. Este es el saber de la novela, el saber al que ha arribado el innombrable como "personaje". Entonces queda todo por decir, al igual que en el principio, solo que ahora el innombrable sabe del habla, sabe que no dará un paso más allá de las palabras, y por lo tanto lo que queda es, a la vez, nada (no "la nada").

\section{BIBLIOGRAFÍA}

Asensi Pérez, Manuel. "Molloy, interrupciones: 'peros' y adversidades". Tentativas sobre Beckett. Ed. Julián Jiménez Heffernan. Madrid: Ediciones Círculo de Bellas Artes, 2007. Pp. 23-55.

Beckett, Samuel. Molloy. Trad. Pedro Gimferrer. Madrid: Alianza, 1970. Molloy. París: Les Éditions de Minuit, 1982. El Innombrable. Trad. R. Santos Torroella. Madrid: Alianza, 1979. L'Innommable. París: Les Éditions de Minuit, 2005. Malone muere. Trad. Ana María Moix. Madrid: Alianza, 1973. Malone meurt. París: Les Éditions de Minuit, 2004.

Begam, Richard. Samuel Beckett and the end of modernity. California: Sandford University Press, 1996.

Cronin, Anthony. Samuel Beckett. El último modernista. Segovia: La Uña Rota, 2012.

De Azúa, Félix. Prólogo a Residua de S. Beckett. Barcelona: Tusquets, 1969. Pp. 9-23. 
De Boisdeffre, Pierre y Melvin Freidmann. Beckett y el fin de la literatura. Ed. Carlos Pérez. Buenos Aires, 1968.

Fifield, Peter. "Samuel Beckett with, in, and around Philosophy". The New Cambridge Companion to Samuel Beckett. Edited by Dirk van Hulle. Cambridge: Cambridge University Press, 2015. 145-157.

García Landa, José. "Lenguaje y Différance en El Innombrable". Actas de las Segundas Jornadas de Lengua y Literatura Inglesa y Norteamericana. Ed. Pedro Santana Martínez. Universidad de La Rioja, 1990. 69-82. https://publicaciones.unirioja.es/catalogo/online/ vr05_IIJornadas.shtml (última modificación: 06/ 06/2013

Kenner, Hugh. Flaubert, Joyce y Beckett. Los comediantes estoicos. México: Fondo de Cultura Económica, 2011.

Konstantinovic, Radomir. Beckett, mi amigo. Barcelona: Littera, 2001.

Stewart, Paul. Zone of Evaporation. Samuel Beckett's Disjunctions. Amsterdam: Editions Rodopi, 2006. 